\title{
LUT
}

University

\section{Agile HRM Practices of SMEs}

Heilmann Pia, Forsten-Astikainen Riitta, Kultalahti Susanna

This is a Final draft version of a publication

published by Wiley

in Journal of Small Business Management

DOI: $10.1111 /$ jsbm.12483

Copyright of the original publication: (C) 2018 International Council for Small Business

Please cite the publication as follows:

Heilmann, P., Forsten-Astikainen, R., Kultalahti, S. (2018). Agile HRM Practices of SMEs. Journal of Small Business Management. DOI: 10.1111/jsbm.12483

This is a parallel published version of an original publication. This version can differ from the original published article. 
Agile HRM Practices of SMEs

Journal of Small Business Management

Pia Heilmann (2018)

There have lately been rising interest relating to human resources $(H R)$ in small and medium-sized companies (SMEs). This study focuses on agile and innovative human resource management (HRM) practices in 100 Finnish SMEs. Chief executive officers (CEOs), HR directors, supervisors, and shop stewards were asked what kinds of agile/innovative HRM practices are present in their company. There are great expectations of SMEs in Finland because the country's economic growth relies on them. Therefore, it is important to pay attention to the more-agile, innovative and productive HRM practices that can nurture profitability and growth among SMEs. 
Agile HRM Practices of SMES

\section{Introduction}

When under threat our first reaction is generally to call upon the fight or flight mechanism. To successfully deal with the threat requires rapid movement and often agility and resilience. An agile management system consists of a proactive management style that deploys human resources efficiently to adapt quickly to positive changes in order to meet customer needs (Crocitto and Youssef 2003; Owusu 1999). However, many organizations seem to adopt only observatory and reactive roles when facing changes around them. From an organizational perspective, performing tasks in a similar way as they were before a change is easier. Traditional, established communities of practices - practices built on common interests and that effectively cross organizational boundaries (Forsten-Astikainen et al. 2017) — are safe and foster peace and harmony in an organization. At the same time, however, many different changes challenge the form of working life and all the activities comprising it. Therefore, it is important to monitor the environment and to learn quickly, and moreover, with a sharp eye on the future. Looking forward, observing silent signals, being motivated to learn, adopting solution-based learning and competence management, and nurturing resilience can be very beneficial when designing the future. Attitude is crucial to SMEs; they must ask themselves if they are going to merely react to change and remain followers, or if they are going to be proactive in change processes and show the way to followers? This article focuses on the agile, effective or innovative HR practices that can be discovered in Finnish SMEs 
and that can increase profitability and growth of SMEs. The key question is how HRM can be done differently and in new, agile, and resilient ways.

The theoretical contribution of this paper is twofold. The first research gap relates to the discussion of HRM practices in SMEs. Previous HRM research primarily focuses on large organizations and relatively little has focused on HR systems within smaller companies (Probst et al. 2011; Edwards et al. 2007; Björkman and Lervik 2007; Cardon and Stevens, 2004; Kelly 2001; Headd, 2000; Heneman et al. 2000; Ferner 1997; Kesler 1995). However, there has recently been evolving interest on HRM in smaller companies (Sheehan 2014; Sherehiy and Karwowski 2014; Verreynne et al. 2013; Klaas et al., 2012; Pankaj and Cardon, 2010). For example, the most recent HRM related concept is humane entrepreneurship (HumEnt) (Kim et al. 2018; Perente et al. 2018). According to HumEnt organizations should focus more to employees, people, environment and society. The HumEnt approach combines entrepreneurship, leadership and HRM perspectives (Kim et al. 2018). The initial concept of HumEnt argued that companies generate higher profits when they respect and encourage employees, rather than lay off workers to cut labor costs, and also when they consider the environment and society at large (Parente et al. 2018). Large companies can usually call upon HR professionals dedicated to addressing the firm's HRM issues, whereas in SMEs, HRM tasks are usually undertaken by CEOs, line managers, or assistants (Klaas et al. 2012). The second research gap relates to the agility discussion relating to HRM practices. Greater size creates stiffness: Within large firms, size and complexity have the potential to create organizational dysfunctions (Klaas et al. 2012). In SMEs, it is easy to follow the operating models of large companies, but imitating large companies can be harmful for SMEs, and they would probably benefit from having the courage to create their own practices and unique operation 
models. This is important because the SME business context is likely to be quite distinctive both in terms of the HRM challenges faced and in terms of how HRM practices can be implemented (Klaas et al. 2012).

The interview data were gathered from 100 Finnish SMEs and such a comprehensive study has not been conducted before. Future Finnish economic growth is expected to be boosted up by SMEs, therefore, it is important to pay attention to the more-agile, innovative and productive HRM practices that can support and enable company's growth. It is a question of fast learning and adjusting operations to meet prevailing circumstances. It is also important to be ready and willing to abandon some traditional communities of practices - informal social structures (Wenger and Lave 1991) - in organizations. Smaller firms are increasingly focusing on utilizing existing resources more efficiently and effectively (Gallego et al. 2012). Smaller companies can act in a more free and agile way, while bigger organizations have more fixed and formal processes. Agility can raise reaction speed and promote economic success and profitability in SMEs (Storey et al. 2010), and it might be possible for large companies to learn something from SMEs' agile operation models, which in many instances are a result of attitude and a courageous re-thinking of current practices: SMEs can make the daring leap, if they want to.

\section{Agility and Resilience}

Haneberg (2011) defined agility as the efficiency with which organizations respond to continuous change by consistently adapting. Agility has been studied, for example, as it relates to data analytics and flows, integration, and supply chains (Spanaki et al. 2017; Chen et al. 2015). Agility 
is important in and more often attached to organizational behavior research and the discussion relating to workforce agility has grown recently (McIver et al., 2018; Muduli, 2016; Sherehiy and Karwowski 2014; Muduli, 2013; Nijssen and Paauwe, 2012; Qin and Nembhard, 2010; Sumukadas and Sawhney, 2004; Katayama and Bennett, 1999). For example, McIver et al. (2018) have examined agile workforce analytics and Muduli (2016) have discovered the role of training, reward system, involvement, team work and information systems in promoting workforce agility.

In a changing business environment, organizations-and the individuals therein-must be more agile and adaptable to responding in small increments that ultimately change the leadership, systems, and culture allowing the firm to survive and prosper in a different environment (Michel 2013). Conner (1998) uses the term nimbleness to describe the ability of an organization to consistently succeed in unpredictable, contested environments by implementing changes more efficiently and effectively than its competitors. According to the definition of Yusuf et al. (1999) organizational agility is successful exploitation of competitive bases (speed, flexibility, innovation proactiveness, quality and profitability) through the integration of reconfigurable resources and best practices in a knowledge-rich environment to provide customer-driven products and services in a fast changing market environment (Yusuf et al., 1999, p. 37). Organizational agility is the ability to make countless small adaptations in response to continual change that result in changing the fundamental building blocks of the organization (Nold and Michel 2016). An agile organization has the ability to respond quickly to competitive threats and market opportunities (Van Assen 2000). Agile workforce is an organized and dynamic talent that can quickly deliver the right skills and knowledge at the right time according to business needs. Agile workforce is well-trained and flexible workforce that can adapt quickly and easily to new opportunities and 
market circumstances. Agile workforce can enhance an organization's ability to survive in a volatile global business environment (Katayama and Bennett, 1999).

Changes challenge HRM practices and the competence of HR professionals. Agility therefore requires implicit leadership that facilitates knowledge sharing, seeks consensus, trusts people, delegates, and provides an environment for people to maximize inherent tacit knowledge (Nold 2012). In the studies of Nold and Michel (2016) agility and speed in decision making become essential capabilities to cope in volatile and uncertain situations. Van Assen (2000) assumes that a central theme within competence management is building and deploying an agile (i.e., an innovative) infrastructure. Moreover, Hamel (2012) emphasized the role of innovation at the core of an agile organization. This kind of agile infrastructure supports development, building, leveraging, and deployment of improved and renewed capabilities and competences. It is a prerequisite for effective and efficient organizational learning. Learning strategies will need to become more agile and respond quickly to change (Miles 2013). On a personal level it is essential to develop new employee skills and competences more rapidly, more often, and in such a way that they have a significant impact than earlier by using wider range of methods, tools, and technologies.

Agile HRM practices can be strategy-based and proactive when HRM is strictly related to business strategy (Nolan and Garavan 2016; Kock and Ellström 2011). The agility discussion is future- and growth-oriented: it emphasizes the importance of learning and competence management. In a healthcare case study, Shafer et al. (2001) discovered several agile, resilient, or nimble HRM attributes as part of the case organization's human resource strategy process. These 
agile characteristics related to flexible work arrangements, blended assignments, needs assessment, ad hoc learning, recognizing/appreciating/celebrating and position reevaluation. These attributes enriched work, promoted personal growth, and provided commensurate returns (Shafer et al. 2001, 200). Tripp et al. (2016) also found support for the positive effect of agile practices on job satisfaction.

Resilience is a concept that can be attached to the agility discussion. Resilience can be accumulated through education, training, working experience, knowledge specific to a company or task, and personality traits relevant to working efficiently. Resilience as an organizational capability helps an organization to recover rapidly from shocks or crises; to anticipate emerging trends; and constantly adapt to change. Human resources practices influence a company's outcomes and its resilience: skilled workers are able to apply innovations faster, and therefore reduce a company's adjustment costs. There is a widespread belief that learning is the core factor required to increase human capital, and a capacity for resilience relates to learning activity (Blanco and Montes-Botella 2017)

According to Sharma and Sharma (2016) team resilience is the ability of teams or groups to recover from adverse conditions. Research reveals that resilient teams are more likely to be productive, agile, and innovative during turbulent times. Research on agility and resilience is relatively scarce, and especially with regard to SMEs. However, Janhonen and Taipale (2017) recently interviewed CEOs and HR professionals in 15 growth companies to investigate agility and resilience. With regard to the agility concept, the study identified three levels of agility: organizational, team, and individual agility. First, on the organizational level, agility refers to 
organizational learning targeting continuous development and engagement. Second, agile organizations employ professional and self-managed teams that are permitted considerable autonomy. Third, an agile individual behaves pro-actively and pursues continuous selfdevelopment.

\section{HRM Practices}

Previous research has established the link between HRM practices and organizational performance, suggesting that the HRM system has great strategic potential to drive organizational effectiveness (Kim et al. 2018; Parente et al. 2018; Sheehan 2014; Saridakis et al. 2013; Verreynne et al. 2013; Heneman and Milanowski 2011; Razouk 2011; Messersmith and Guthrie 2010).

It has been argued that when appropriately configured and directed, HRM is effective in encouraging greater job performance and wider extra-role contributions to the organization (Becker and Huselid 2006). Small firms need to be particularly focused on maximizing employee productivity (Pankaj and Cardon 2010; Williamson et al. 2002) and HRM practices can positively affect a firm's performance (Becker and Huselid 1998; Ulrich 1997). The recent study of Sheehan (2014) showed that there are significant positive returns in terms of increased profitability, innovation and reduced labor turnover associated with investment in human resources by SMEs.

Some HRM practices are obligatory and legal requirements and some are based more on organizational needs. HRM practices include: organizational design, workforce planning, recruitment, selection, placement, commitment, loyalty, contract termination, employee 
engagement, performance management, leadership, managing attendance and absence, change and development, performance management, knowledge management, career management, motivation, compensation, benefits and services, organizational/employee learning, work time control, information sharing, equality, diversity management, discipline, rewards, talent management, ethics, labor relations, corporate social responsibility, IT in HR, health and wellbeing, the work-life balance, downsizing, flexibility, communication, and global HRM (Truss et al. 2012; Torrington et al. 2011; Redman and Wilkinson 2009; Dessler 2008). However, it is not necessary for SMEs to adopt all HRM practices and use them simultaneously (Bloom and Van Reenan 2007; Sels et al. 2006). HRM practices can be used, bundled, and emphasized differently in different organizations.

It can easily be argued that smallness promotes agility. Managers of small firms are seldom formally trained in implementing HRM practices, and the firms do not necessarily have any developed HRM structures, formal HRM policies, or programs (Heneman and Tansky 2002). The HRM knowledge in SMEs is often tacit (i.e., it is unarticulated, follows informal guidelines, and is intuitive) and, thus, is not easily codified and transmitted (Klaas et al. 2012). Informal HR practices in SMEs can relate, for example, to on-the-job staff training, learning by doing, monitoring and exit interviews (Cameron et al. 2006). Those small firms that tend to rely solely on informal processes in HR (Davil 2005; Cardon, and Stevens 2004), are likely to be missing out on this opportunity to produce satisfying HRM outcomes. However, there is a need for both formal and informal HRM procedures. Formality and informality is like to be dynamic, reflecting both internal and external contingency factors (Ram et al. 2001). 
According to Nold and Michel (2016), agility in the twenty-first century is dependent on blending culture, leadership, and systems in a way to maximize knowledge flow throughout the organization to develop dynamic capabilities and facilitate effective and timely decision making. Anything less and the organization will fail to perform optimally and ultimately be overtaken by competitors who are more agile.

SMES

There are around 285000 enterprises in Finland excluding agricultural, forestry and fishery companies (Statistics Finland 2015). Those companies employ 1.4 million people and 93 percent of the firms employ fewer than 10 people. During the 2000s, most of the new firms established were SMEs. Finnish SMEs account for 58 percent (EUR 379 billion) of the total turnover of Finnish companies and for 40 percent of the gross domestic product of Finland.

Different enterprises can be grouped by size. Micro enterprises employ fewer than 10 people, around 265000 , or 93 percent of the total. Enterprises that employ fewer than 50 people are small enterprises and around 15600 , or 5.5 percent of the total. Companies that employ 50-249 people are middle-sized enterprises and number 2600 , or 0.9 percent of the total. Firms that employ more than 249 people are large enterprises and number 57, or 0.2 percent of the total (Statistics Finland 2015).

\section{Method}


The article is based on research data gathered in Finland 2016-2017. The data include 255 structured interview answers gathered from 100 Finnish SMEs employing 20-250 people. The companies represented different fields of business but the biggest group was productive technology companies (12/100). The SMEs were located all over Finland but the majority came from the West, the East and the South-East Finland. The current data was a part of a bigger HRM data but only the answers relating to agile HRM practices were used in this article. CEOs, HR directors, supervisors, and shop stewards from each company were asked what kinds agile/innovative HRM practices exist in their company. Every interviewee mentioned one or more HRM practices that they understood to be in some way agile. The qualitative analysis was undertaken with the content analysis method where the interview data were thematically coded. Answers were examined to find different agile HRM practices in relation to previous HRM literature (see for example Truss et al. 2012; Torrington et al. 2011; Redman and Wilkinson 2009; Dessler 2008). Mentions were count and grouped under each HRM theme. Thereafter the percentage of each HRM theme could be presented. The thematic codes identified were then grouped into 11 HRM themes.

\section{Results}

Agile HRM practices in SMEs seem to relate to the following 11 themes: working hours, organizing, cooperation, work wellbeing practices, leadership, development, interaction, work place, work-family balance, recruitment, and work equipment (see Table 1 for summaries). 
Table 1

Agile HRM Practices in SMEs

Insert Table 1 here

The 255 structured interview answers included 330 separate mentions that were compiled into 11 HRM themes. The agile HRM practices most-often mentioned were flexible working hours, organizing, and cooperation. The CEOs, HR directors, supervisors, and shop stewards discussed the following agile HRM processes, among others:

\section{Working Hours (90 mentions / 27\%)}

"Working hours account gives flexibility"

"Flextime"

"You can get free time when needed"

\section{Organizing (60 mentions / 18\%)}

"We can transfer resources between the departments"

"Job rotation is practical"

"Electrical systems, smart phones, everything has been programmed to a cell phone" "Micro-loans for personnel"

\section{Cooperation (45 mentions / 14\%)}


"People from the machine shop can participate in product development and really affect it" "Personnel can participate in strategy building"

"Possibility to participate in development work"

\section{Work Wellbeing (36 mentions / 11\%)}

"Sending 'sun-messages' (support) to colleagues"

"Brunch"

"Online work wellbeing programs"

"Remolding the work content when working ability changes"

\section{Leadership (33 mentions / 10\%)}

"Development discussion, targets are generated bottom-up"

"The managerial group dares to try new procedures"

"New meeting practice: 'Move faster - pulse faster""

\section{Development (21 mentions / 6\%)}

"Distribution of skills and competences"

"Innoteam - work development team"

"Crazy ideas will be tried out, e.g. the 'Hair-Hassle'-event"

\section{Interaction (17 mentions / 5\%)}

"Open dialog across organizational limits and levels"

"Work is not so rigid, we have an unaffected atmosphere" 
"Possibility for discussion, you don't only have to follow orders"

\section{Work Place (16 mentions / 5\%)}

"Work is done wherever is the most suitable place for it"

"Programs and tools that enable remote work"

"Possibility to start working in Lapland"

\section{Work-family Balance (7 mentions / 2\%)}

"Also private life is recognized"

"We are flexible relating to needs coming from private life"

"We flex for child care reasons"

\section{Recruitment (3 mentions / 1\%)}

"Facebook as a recruitment channel is very innovative"

"Homework given to the applicant in the recruitment situation"

"Simulation test for software developer applicants"

\section{Work Equipment (2 mentions / 1\%)}

"WhatsApp group"

"We have proper tools"

\section{Discussion and Conclusions}


The current study makes contributions to two main areas of research. The first of contribution relates to the discussion of HRM practices in SMEs. The second area is the agility discussion relating to HRM practices in SMEs. Previous HRM research largely focuses on large organizations and there is little research focused on human resource systems within the smaller companies (Probst et al. 2011; Edwards et al. 2007; Björkman and Lervik 2007; Cardon and Stevens, 2004; Kelly 2001; Headd, 2000; Heneman et al. 2000; Ferner 1997; Kesler 1995).

A typical feature of an agile management system is a proactive and forward-looking management style, where human resources are efficiently used to adapt quickly to changes (Muduli 2016; Crocitto and Youssef 2003; Owusu 1999). HRM practices in the studied SMEs seem to be quite traditional rather than noticeably agile, practical, or innovative. That is interesting when SMEs enjoy potential advantages over larger businesses conferred by their smaller size, reduced hierarchy, and often having fewer formal HRM procedures.

It seems that many SMEs have adopted the HRM operation models of large companies with considerable HR resources, tight rules, targets, budgets, plans, and compensation models. The easiest way seems to be to copy HRM models from bigger companies instead of thinking of the most suitable and agile HRM practices for the particular SME. The agile and innovative HRM practices that were found, seem to be based on SMEs own cultural needs and to be fostered in firms courageous enough to do things in their own way.

If an SME is to be successful, it is valuable that it creates its own communities of practices and unique operation models as well as developing the ability to make rapid decisions (Nold and 
Michel 2016; Klaas et al. 2012). It looks like there is not necessarily enough time, or courage, to devise individual HRM processes and practices suited specifically to the SME's own vision or mission. There is a need to consider the strategic objectives of the company and think what role will be required of $\mathrm{HR}$ in implementing them. The speed with which environmental changes can affect a firm requires agility in organizational systems, leadership practices, and culture (Michel 2013).

In this study, 11 HRM themes were discovered that included some form of agility processes. Agile practices cannot be implemented and used to the same extent for every HRM function. The agile HRM practices that were mentioned most often concerned flexible working hours, organizing, organizational cooperation, work wellbeing, leadership, development, interaction, work place, work-family balance, recruitment and work equipment. Flexibility in terms of working hours relates to organizing and adjusting time in the form of daily, weekly, or monthly working hours. Such flexible time arrangements seem to be relatively easy to organize in a firm if there is a willingness to do so. The staff appreciates flextime arrangements because individual life situations vary over the course of a career. Such situations benefiting from flexible working time might include needing to care for children or elderly relatives or, for example, a break for house building. Personnel in SMEs also appreciate flat hierarchies and ease of communication. Moreover, in the area of workplace wellbeing there are great opportunities for SMEs to create their own agile, practicable or innovative practices. SMEs should take the initiative and consider new models for promoting workplace wellbeing practices drawn from their own organizational needs. Remote working or telecommuting, while not feasible in every profession, can offer practical agile solutions that can increase workplace wellbeing and also decrease traveling costs. Such flexibility 
relating to the workplace can be applied among specialists but is not necessarily possible in manufacturing or service organizations. Work wellbeing can be improved through different health events and programs relating to exercising and nutrition. For example, vegetable-fruit Friday. Leadership skills of managers can be developed through education, coaching and mentoring. Agile HRM practices in SMEs related also to development and to innovation promotion. As well, agile HRM practices appeared in interaction with organization members, how people communicated or treated and helped one another. For example: 'thank you'-flip chart for personnel, 'blunder'-flip chart for personnel or organizing meetings that are dedicated only for complaining. Work and family balance can be improved more agile way. For example, organizations can offer free temporary childcare for employees' sick children. Agile recruitment methods can relate to new ways of networking and informing about the open positions. Also homework can be given to the applicant in the recruitment situation. Social media can be used more effectively in recruitment marketing and employer brand image creation. Work equipment can be agile as well: new technological solutions, such as mobile tools, smartphones and software applications, can enable better work processes.

The agile HRM practices elicited in this study seem to be based on SMEs' own cultural needs, and their implementation seems to require courageous thinking and a willingness to do things in the firm's own way. Communities of practices focus attention on the work at the grassroots level and are open to ideas that come from employees. In communities, membership is based on participation related to a shared concern or problem, or passion, for example (du Plessis 2008), rather than on official status. Daring to think new way together is essential. It is important to transmit knowledge, competences, and experiences (McDermott, 1998) and not resist or obstruct 
emerging new ideas. This kind of thinking seems to release innovativeness, involvement, and to promote cooperation, which are the key promoters of agility and resilience in developing organizations.

\section{Further Research}

It remains to be seen if the recently outlined "teal management" perspective (Laloux 2015; 2014) offers a useful tool for organizations to become more agile in the future. Teal management relates to participation and shared decision making, the impact of personality on work, selfleadership, competence development, and an emphasis on good work. The key components of teal management are self-management, wholeness, and an evolutionary purpose. First, teal organizations operate effectively with a system based on peer relationships. They set up structures and practices in which people have high levels of autonomy in their domain, and are accountable for coordinating with others. Power and control are deeply embedded throughout the organizations, that is, no longer tied to the specific positions of a few top leaders. Second, teal organizations invite people to reclaim their inner wholeness. They create an environment where people are free to express themselves, bringing their energy, passion, and creativity to work. Third, teal organizations base their strategies on what they sense the world is asking from them. In teal organizations agile practices can replace tight rules, targets, budgets, plans, and compensation models. Paradoxically, by focusing less on the bottom line and shareholder value, they often generate financial results that outpace those of their competitors (Laloux 2015; 2014). In conclusion, involvement at both individual and organizational levels is valuable when creating agile and resilient HRM practices in SMEs. 


\section{Practical Implications}

The results of this research have important implications for daily operation models in SMEs. It can be suggested that SMEs should dare to face the risk of failure when deciding upon and implementing their own HRM practices. An innovative attitude, as well as questioning, risktaking, and trial and error promote learning. But in many cases, it is a question of daring; courage calls for the right kind of innovativeness. Agile startups in the Silicon Valley have embraced the "fail fast, fail often, fail forward" way of thinking. It is a question of daring and changing the mindset: If you fail, fail smart and learn. Agile, practicable, or innovative HRM practices can be designed from an SME's own missions and visions but development needs time to consider organizational culture, objectives, and the questioning of a firm's own routines. Of course, organizations can learn from other organizations by doing benchmarking and co-operation. Nevertheless, it is of course a question of resources but also courage and willingness to start thinking about HR in a new way and then deciding where to start. The best agile HRM practices developed in SMEs could well be applied to large companies, as well as to public sector organizations. Summing up, the more-agile HRM practices promote organizational effectiveness.

\section{References}

Becker, B.E. and Huselid M.A. (2006). "Strategic human resources management: Where do we go from here?" Journal of Management 32(6), 898-925. 
Becker, B. E., and Huselid, M. A. (1998). "High performance work systems and firm performance: A synthesis of research and managerial implications," in Research in Personnel and Human Resource Management Ed. G. R. Ferris. Stamford, CT: JAI Press. 16, 53-101.

Björkman I. and Lervik J. E. (2007). "Transferring HR practices within multinational corporations," Human Resource Management Journal 17(4), 320-335.

Blanco J. M. M. and Montes-Botella J-L. (2017). “Exploring nurtured company resilience through human capital and human resource development Findings from Spanish manufacturing companies," International Journal of Manpower 38(5), 661-674.

Bloom, N., and Van Reenen, J. (2007). Measuring and explaining management practices across firms and countries. Quarterly Journal of Economics, 122(4), 1351-1408.

Cameron A., Coetzer A., Lewis K., Claire M. and Candice H. (2006). "HR Management Practices: Home-Grown, But Effective," Chartered Accountants Journal. November.

Cardon, M. S. and Stevens, C. E. (2004). "Managing human resources in small organizations: What do we know?" Human Resource Management Review 14, 295-323.

Chen, K., Li X. and Wang H. 2015. "On the model design of integrated intelligent big data analytics systems," Industrial Management and Data Systems 115(9), 1666-1682. 
Conner D. R. (1998). "How to create a nimble organization," National Productive Review. Autumn.

Crocitto, M. and Youssef, M. (2003). “The human side of organizational agility," Industrial Management and Data Systems 103(6), 388-397.

Davil, T. (2005). “An exploratory study on the emergence of management control systems: Formalizing human resources in small growing firms," Accounting, Organizations and Society 30, $223-248$.

Dessler, G. (2008). Human resource management 11 th ed., Pearson, Prentice Hall, Upper Saddle River, NJ.

du Plessis, M. (2008). “The strategic drivers and objectives of communities of practice as vehicles for knowledge management in small and medium enterprises," International Journal of Information Management 28(1), 61-67.

Edwards T., Colling T. and Ferner A. (2007). "Conceptual approaches to the transfer of employment practices in multinational companies: An integrated approach," Human Resource Management Journal 17(3), 201-217.

Ferner A. (1997). "Country of origin effects and HRM in multinational companies," Human Resource Management 7(1), 19-37. 
Forsten-Astikainen R., Hurmelinna-Laukkanen P., Lämsä T., Heilmann P. and Hyrkäs E. (2017). "Dealing with organizational silos with communities of practice and human resource management," Journal of Workplace Learning 29(6), 473-489.

Gallego, J., Rubalcaba, L. and Hipp, C. (2012). “Organisational innovation in small European firms: a multidimensional approach,” International Small Business Journal, 31(5) 563-579.

Hamel, G. (2012). "What matters now: How to win a world of relentless change, ferocious competition, and unstoppable innovation," Josey-Bass, San Francisco, CA.

Haneberg, L. (2011). “Training for agility,” Training and Development 65(9), 50-55.

Headd, B. (2000). "The characteristics of small business employees," Monthly Labor Review 123, $13-18$.

Heneman III H. G. and Milanowski A. T. (2011). “Assessing human resource practices alignment: A case study," Human Resource Management 50(1), 45-64.

Heneman, R. L., and Tansky, J. W. (2002). "Human resource management models for entrepreneurial opportunity: Existing knowledge and new directions," in Managing people in entrepreneurial organizations. Eds. Katz J. and Welbourne T. M. 5, 55-82. Amsterdam: JAI Press. 
Heneman, R. L., Tansky, J. W., and Camp, S. M. (2000). "Human resource management in small and medium-sized enterprises: Unanswered questions and future research perspectives," Entrepreneurship Theory and Practice 25, 11-26.

Janhonen, M. and Taipale, T. (2017). "Informal human resource principles and practices as a key to growth," in: Navigating through changing times knowledge work in complex environments. Ed. A. Eskola. Routledge.

Katayama H. and Bennett D. (1999). "Agility, Adaptability and Leanness: A Comparison of Concepts and a Study of Practice", International Journal of Production Economics, 60 \& 61, 4351.

Kelly J. (2001). "The role of the personnel/HR function in multinational companies" Employee Relations 23(6), 536-557.

Kesler G. C. (1995). “A model and process for redesigning the HRM role, competences and work in a major multi-national corporation," Human Resource Management 34(2), 229-252.

Klaas B. S., Semadeni M., Klimchak M. and Ward A-K. (2012). "High-performance work system implementation in small and medium enterprises: A knowledge-creation perspective" Human Resource Management 51(4), 487-510. 
Kim K-C, ElTarabishy A. and Bae Z-T. (2018). "Humane entrepreneurship: How focusing on people can drive a new era of wealth and quality job creation in a sustainable world" Journal of Small Business Management 56(S1), 10-29.

Kock, H. and Ellström, P-E. (2011). "Formal and integrated strategies for competence development in SMEs,” Journal of European Industrial Training 35(1), 71-88.

Laloux F. (2015). "The future of the management is teal” Strategy and Leadership.

Laloux, F. (2014). Reinventing organizations, Nelson Parker, Brussels, Belgium.

Messersmith J. G. and Guthrie J. P. (2010). "High performance work systems in emergent organizations: Implications for firm performance," Human Resource Management 49(2), 241264.

McDermott, R. (1998). "Learning across teams: the role of communities of practice in team organizations," Knowledge Management Review 11(2), 1-8.

McIver D., Lengnick-Hall M. L. and Lengnick-Hall C. A. (2018). “A strategic approach to workforce analytics: Integrating science and agility”, Business Horizons 61(3), 397-407.

Michel, L. (2013). The performance triangle: Diagnostic mentoring to manage organizations and people for superior performance in turbulent times. LID Publishing, London. 
Miles, A. (2013). "Agile learning: Living with the speed of change," Development and Learning in Organizations 27(2), 20-22.

Muduli, A. (2016). "Exploring the facilitators and mediators of workforce agility: an empirical study” Management Research Review 39(12), 1567-1586.

Muduli, A. (2013). "Workforce Agility: A Review of Literature", IUP Journal of Management Research 12(3), 55-65.

Nijssen M. and Paauwe J. (2012). "HRM in turbulent times: how to achieve organizational agility?" The International Journal of Human Resource Management 23(16), 3315-3335.

Nolan, C. and Garavan, T. (2016). "Problematizing HRD in SMEs. A "Critical" exploration of context, informality, and empirical realities" Human Resource Development Quarterly 27(3), 407442.

Nold, H. (2012). "Linking knowledge processes with firm performance: organizational culture," Journal of Intellectual Capital 13(1), 16-38.

Nold, H. and Michel, L. (2016). "The performance triangle: a model for corporate agility," Leadership and Organization Development Journal 37(3), 341-356. 
Owusu Y. A. (1999). "Importance of employee involvement in world-class agile management systems," International Journal of Agile Management Systems 1, 107-115.

Pankaj, C. P. and Cardon, M. S. (2010). “Adopting HRM practices and their effectiveness in small firms facing product market competition” Human Resource Management 49(2), 265-290.

Parente R., ElTarabishy A., Vesci M. and Botti A. (2018). "The epistemology of humane entrepreneurship: Theory and proposal for future research agenda" Journal of Small Business Management 56(S1), 30-52.

Probst G, Raisch S. and Tuschman M. L. (2011). “Ambidextrous leadership: Emerging challenges for business and HR leaders," Organizational Dynamics 40, 326-334.

Qin R. and Nembhard D. A. (2010). "Workforce agility for stochastically diffused conditions-A real options perspective” International Journal of Production Economics 125(2), 324-334.

Ram M., Edwards P., Gilman M., and Arrowsmith, J. (2001). “The Dynamics of Informality Employment Relations in Small Firms and the Effects of Regulatory Change," Work, Employment and Society 15(4), 845-86.

Razouk A. A. (2011). "High-performance work systems and performance of French small- and medium-sized enterprises: examining causal order," The International Journal of Human Resource Management 22(2), 311-330 
Redman, T. and Wilkinson, A. (2009). Contemporary human resource management. Text and Cases..3rd ed., Prentice Hall, Harlow.

Saridakis G., Yanqing L. and Cooper L. (2017).”Exploring the relationship between HRM and firm performance: A meta-analysis of longitudinal studies," Human Resource Management Review 27, 87-96.

Sels, L., De Winne, S., Delmotte, J., Maes, J., Faems, D., and Forrier, A. (2006). “Linking HRM and small business performance: An examination of the impact of HRM intensity on the productivity and financial performance of small businesses," Small Business Economics 26(1), 83-101.

Sharma S. and Sharma S. K. (2016). "Team Resilience: Scale Development and Validation," Vision 20(1), 37-53.

Shafer R. A., Dyer L., Kilty J., Amos J. and Ericksen J. (2001). "Crafting a Human Resource Strategy to Foster Organizational Agility: A Case Study," Human Resource Management 40(3), 197-211.

Sheehan M. (2014). "Human resource management and performance: Evidence from small and medium-sized firms," International Small Business Journal 32(5) 545-570. 
Sherehiy B. and Karwowski W. (2014). "The relationship between work organization and workforce agility in small manufacturing enterprises", International Journal of Industrial Ergonomics 44(3), 466-473.

Spanaki K., Gürgüç Z., Adams R. and Mulligan C. (2017). "Data supply chain (DSC): research synthesis and future directions", International Journal of Production Research, accepted 15 October 2017.

Statistics of Finland (2018). https://www.yrittajat.fi/suomen-yrittajat/yrittajyys-suomessa-316363. 18 January 2018.

Storey, D., Saridakis, G., Sen-Gupta, S., Edwards, P. and Blackburn, R. (2010). "Linking HR formality with employee job quality: The role of firm and workplace size," Human Resource Management 49(1), 305-329.

Sumukadas, N. and Sawhney, R. (2004). "Workforce agility through employee involvement", IIE Transactions, 36, 1011-1021.

Torrington, D., Hall, L., Taylor, S. and Atkinson, C. (2011). Human resource management. 8th ed., Prentice Hall, Harlow. 
Tripp J. F., Riemenschneider C. and Thatcher J. B. (2016). “Job satisfaction in agile development teams: Agile development as work redesign," Journal of the Association of Information Systems 17(4), 267-307.

Truss, C., Mankin, D. and Kelliher, C. (2012). Strategic human resource management. Oxford University Press, Oxford.

Ulrich, D. (1997). Human resource champions: The next agenda for adding value and delivering results. Cambridge, MA: Harvard Business School Press.

Van Assen, M. F. (2000). “Agile-based competence management: The relation between agile manufacturing and time-based competence management," International Journal of Agile Management Systems 2(2), 142-155.

Wenger, E. and Lave, J. (1991). Situated Learning: Legitimate Peripheral Participation. Harvard University Press, Cambridge, MA.

Verreynne M-L., Parker P. and Wilson M. (2013). "Employment systems in small firms: A multilevel analysis," International Small Business Journal 31(4) 405-431.

Williamson, I. O., Cable, D. M., and Aldrich, H. E. (2002). "Smaller but not necessarily weaker: How small businesses can overcome barriers to recruitment" in Managing people in 
entrepreneurial organizations: Learning from the merger of entrepreneurship and human resource management. Eds. J. Katz and T. M. Welbourne. Amsterdam: JAI Press, 83-106.

Yusuf Y., Sarhadi M. and Gunasekaran A. (1999). "Agile Manufacturing: The Drivers, Concepts and Attributes", International Journal of Production Economics, 62, (1 \& 2) 33-43. 
Table 1

\section{Agile HRM Practices in SMEs}

\begin{tabular}{|l|l|}
\hline Working hours & Work hours account, flexible working hours \\
\hline Organizing & Organizing work, job rotation, flat organization structure \\
\hline Cooperation & Participation, cooperation, team working \\
\hline Work wellbeing & Wellbeing activities, leisure activities, occupational health \\
\hline Leadership & Leading personnel, supervision \\
\hline Development & Brainstorming, innovativeness, overall development, competences \\
\hline Interaction & Interaction, atmosphere, organization citizenship behavior \\
\hline Work place & Remote work, different work places \\
\hline Work-family balance & Opportunity to have both work and family \\
\hline Recruitment & Hiring new personnel \\
\hline Work equipment & Tools, materials, equipment \\
\hline
\end{tabular}

